\title{
Letter
}

\section{Identifying the Hydrogenated Planar Tetracoordinate Carbon: A Combined Experimental and Theoretical Study of CAl4H and CAl4H\#}

\author{
Jing Xu, Xinxing Zhang, Shuang Yu, Yi-Hong Ding, and Kit Hansell Bowen
}

J. Phys. Chem. Lett., Just Accepted Manuscript • Publication Date (Web): 04 May 2017

Downloaded from http://pubs.acs.org on May 5, 2017

\section{Just Accepted}

"Just Accepted" manuscripts have been peer-reviewed and accepted for publication. They are posted online prior to technical editing, formatting for publication and author proofing. The American Chemical Society provides "Just Accepted" as a free service to the research community to expedite the dissemination of scientific material as soon as possible after acceptance. "Just Accepted" manuscripts appear in full in PDF format accompanied by an HTML abstract. "Just Accepted" manuscripts have been fully peer reviewed, but should not be considered the official version of record. They are accessible to all readers and citable by the Digital Object Identifier (DOI®). "Just Accepted" is an optional service offered to authors. Therefore, the "Just Accepted" Web site may not include all articles that will be published in the journal. After a manuscript is technically edited and formatted, it will be removed from the "Just Accepted" Web site and published as an ASAP article. Note that technical editing may introduce minor changes to the manuscript text and/or graphics which could affect content, and all legal disclaimers and ethical guidelines that apply to the journal pertain. ACS cannot be held responsible for errors or consequences arising from the use of information contained in these "Just Accepted" manuscripts. 


\title{
Identifying the Hydrogenated Planar Tetracoordinate
}

\section{Carbon: a Combined Experimental and Theoretical} Study of $\mathrm{CAl}_{4} \mathrm{H}$ and $\mathrm{CAl}_{4} \mathrm{H}^{-}$

\author{
Jing Xu, ${ }^{\S,{ }^{\xi},+}$ Xinxing Zhang, ${ }^{*}{ }^{*+}$ Shuang Yu, ${ }^{\S}$ Yi-hong Ding, ${ }^{*}{ }^{s}$ and Kit H. Bowen ** \\ ${ }^{\S}$ Laboratory of Theoretical and Computational Chemistry, Institute of Theoretical Chemistry, \\ Jilin University, Changchun 130023, People’s Republic of China. \\ Noyes Laboratory of Chemical Physics and the Beckman Institute, California Institute of \\ Technology, Pasadena, California, 91125, USA. \\ ${ }^{\ddagger}$ Departments of Chemistry and Material Sciences, Johns Hopkins University, Baltimore, \\ Maryland, MD 21218, USA.
}

\section{AUTHOR INFORMATION}

Corresponding Author

*E-mail: zhangx@caltech.edu ;*E-mail: yhdd@jlu.edu.cn ;*E-mail: kbowen@jhu.edu 


\begin{abstract}
The chemical curiosity "planar tetracoordinate carbon" (ptC) has greatly broadened one's knowledge of molecular bonding motifs apart from the traditional, tetrahedral, van't Hoff and LeBel's concept. Synthesized ptC examples have been reported either in solid state or in the gas phase, where the $\mathrm{ptC}$ core is usually metalized or organometallized. Surprisingly, there has been no experimental report on hydrogenated ptC to date. A possible answer to this situation could be the "promiscuity" of hydrogen when binding to other elements, which frustrates the formation of stable $\mathrm{ptC}$ that is in competition with other structures. In this paper, we for the first time identified two hydrogenated ptC species, $\mathrm{CAl}_{4} \mathrm{H}$ and $\mathrm{CAl}_{4} \mathrm{H}^{-}$, based on a photoelectron spectroscopic and quantum chemical study. The favorable site-selectivity of hydrogen was shown to be the bridge of Al-Al bond rather than the terminus of Al, manifesting the thermodynamic preference of $17 \mathrm{e} / 18 \mathrm{e}$ counting rule over the $15 \mathrm{e} / 16 \mathrm{e}$ rule.
\end{abstract}

\title{
TOC GRAPHICS
}

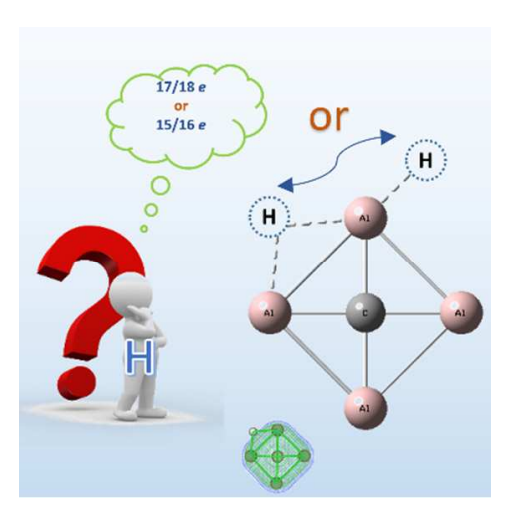


Planar tetracoordinate carbon ( $\mathrm{ptC}$ ) has witnessed tremendous advancement in the past fifty years. ${ }^{1,2}$ First proposed by H. J. Monkhorst in $1968,{ }^{3}$ the designed planar methane was nevertheless an unstable transition state. Subsequently, Hoffmann et al. proposed two strategies to stabilize $\mathrm{ptC}^{4}$, which have been a general guide to design $\mathrm{ptC}$ species. One is the mechanical strategy, which often makes use of transition metals, conjugative rings or cages to forcibly form $\mathrm{ptC}$. The other is the electronic strategy, which introduces strong $\sigma$-donor and $\pi$-acceptor ligands or aromatic delocalization to stabilize the $p$-type lone pair on the $\mathrm{ptC}$ center. Based on the above two strategies, Schleyer and coworkers theoretically designed the first group of ptC molecules (even though not global minimum) in $1976 .{ }^{5}$ Since then, the ptC chemistry has been widely developed theoretically, ${ }^{1,2}$ and has been extended to planar high-coordinate carbon ${ }^{6-8}$ or planar tetra-/high-coordinate $X(X \text { could be other main group elements })^{9-11}$ as well as the nano-sized systems for potential applications in materials science. ${ }^{12-14}$

In parallel, there have been some experimental investigations on $\mathrm{ptC}^{15} \mathrm{~A}$ class of organometallic ptC have been synthesized in solid state, ${ }^{16}$ but such compounds are usually structurally complicated and involve metals or transitional metals as ligands to kinetically stabilize the ptC unit. By contrast, in 1999, a simple penta-atomic ptC cluster $\mathrm{CAl}_{4}{ }^{-}$was detected in the gas phase. ${ }^{17}$ One year later, several new ptC species, i.e., $\mathrm{CAl}_{3} \mathrm{Si}^{-}, \mathrm{CAl}_{3} \mathrm{Ge}^{-}, \mathrm{CAl}_{4}{ }^{2-}$ and $\mathrm{NaCAl}_{4}^{-}$, were characterized. ${ }^{18-20}$ To understand the bonding and stability of these species, an effective valence electron-counting rule, namely the "18ve-rule", ${ }^{21}$ has been devised and found applicable in many systems. ${ }^{22}$ Note that this rule differs sharply from the one mainly associated with compounds composed of transition metal atoms such as $\mathrm{Cr}\left(\mathrm{C}_{6} \mathrm{H}_{6}\right)_{2}$ and $\mathrm{Fe}\left(\mathrm{C}_{5} \mathrm{H}_{5}\right)_{2}$ where 18 valence electrons are needed to close the $\mathrm{s}, \mathrm{p}$, and $\mathrm{d}$ shells ${ }^{23-25}$ Besides, there is an increasing consensus that a ptC structure should better have the lowest energy (or be the global minimum) 
to allow its experimental observation under annealing conditions. ${ }^{26}$ Moreover, the simplicity of these penta-atomic species has allowed them to act as building blocks for more complicated complexes. $^{27-29}$

Clearly, in all the known ptC compounds (except the simplest penta-atomic ptCs), the ptC cores are stabilized by metallic or organometallic ligands. No hydrogenated ptCs have been reported in experiments. By occupying the terminal, bridge or face-sites to adjust the skeletal electrons, fascinating hydrogenated topologies can be achieved in compounds such as boranes, alanes and carboranes. ${ }^{30}$ A plausible explanation for the absence of hydrogenated ptCs could be the structural fragility of ptC, whose stability highly relies on the subtle balance between the electronic and steric factors. Presumably, being promiscuous in bonding possibilities, hydrogenation would cause undesired competition from other nonplanar structures. In this sense, identifying a global minimal hydrogenated $\mathrm{ptC}$ should represent a big challenge for both experiment and theory.

In this paper, based on the anion photoelectron spectroscopy (PES), global structural search and high-level $a b$ initio calculations (see SI for details), we successfully identified two hydrogenated species, $\mathrm{CAl}_{4} \mathrm{H}^{-/ 0}$, both featuring the global minimal ptC. Due to the hydrogen atom's site-selectivity, the observed isomer that fulfills the $17 \mathrm{e} / 18 \mathrm{e}$ rule is energetically more favorable than the one with $15 \mathrm{e} / 16 \mathrm{e}$, this being the first time to experimentally prove the preference of $17 \mathrm{e} / 18 \mathrm{e} \mathrm{ptC}$ over $15 \mathrm{e} / 16 \mathrm{e} \mathrm{ptC}$. The present work not only expands the diversity of $\mathrm{ptC}$, but more importantly, opens a new avenue for the hydrogenated ptC chemistry using the tested electronic counting rules.

Experimental details are presented in the SI. Figure 1 presents a typical mass spectrum containing hundreds of carbon aluminum hydride cluster anions, $\mathrm{C}_{\mathrm{x}} \mathrm{Al}_{\mathrm{y}} \mathrm{H}_{\mathrm{z}}^{-}(\mathrm{x}=0-2, \mathrm{y}=1-9, \mathrm{z}=1-4)$, 
and different ion groups are marked by the number of carbon atoms as $\mathbf{0}$, $\mathbf{1}$, or $\mathbf{2}$. Here we highlight only the group with the highest intensity, circled and expanded in Figure 1; they are the $\mathrm{CAl}_{4} \mathrm{H}_{\mathrm{n}}{ }^{-}(\mathrm{n}=0-3)$ clusters. Those small peaks to the left of $\mathrm{CAl}_{4}{ }^{-}$are corresponding to the $\mathrm{C}_{3} \mathrm{Al}_{3} \mathrm{H}_{\mathrm{n}}{ }^{-}$series. By minimizing the carbon powder ratio in the carbon aluminum mixture, we managed to lower the $\mathrm{C}_{3} \mathrm{Al}_{3} \mathrm{H}_{\mathrm{n}}{ }^{-}$signal as much as possible in order to make sure $\mathrm{C}_{3} \mathrm{Al}_{3} \mathrm{H}_{\mathrm{n}}{ }^{-}$did not contaminate the photoelectron spectra of $\mathrm{CAl}_{4} \mathrm{H}_{n}{ }^{-}$. In the $\mathrm{CAl}_{4} \mathrm{H}_{n}{ }^{-}(\mathrm{n}=0-3)$ series, $\mathrm{CAl}_{4} \mathrm{H}^{-}$ possesses overwhelmingly higher intensity. It is not only the strongest peak in the neighborhood, but also the strongest peak in the entire mass spectrum that contains hundreds of clusters, indicating highly unusual stability of the $\mathrm{CAl}_{4} \mathrm{H}_{1}{ }^{-}$cluster. This observation is reasonable in the sense that $\mathrm{CAl}_{4} \mathrm{H}^{-}$is closed shell and $\mathrm{CAl}_{4} \mathrm{H}_{0,2}{ }^{-}$are open shell. However, this conventional wisdom does not apply to $\mathrm{CAl}_{4} \mathrm{H}_{3}{ }^{-}$, which is also closed shell, suggesting that there must be more stabilizing effect contributing to the high intensity of $\mathrm{CAl}_{4} \mathrm{H}^{-}$(vide infra).

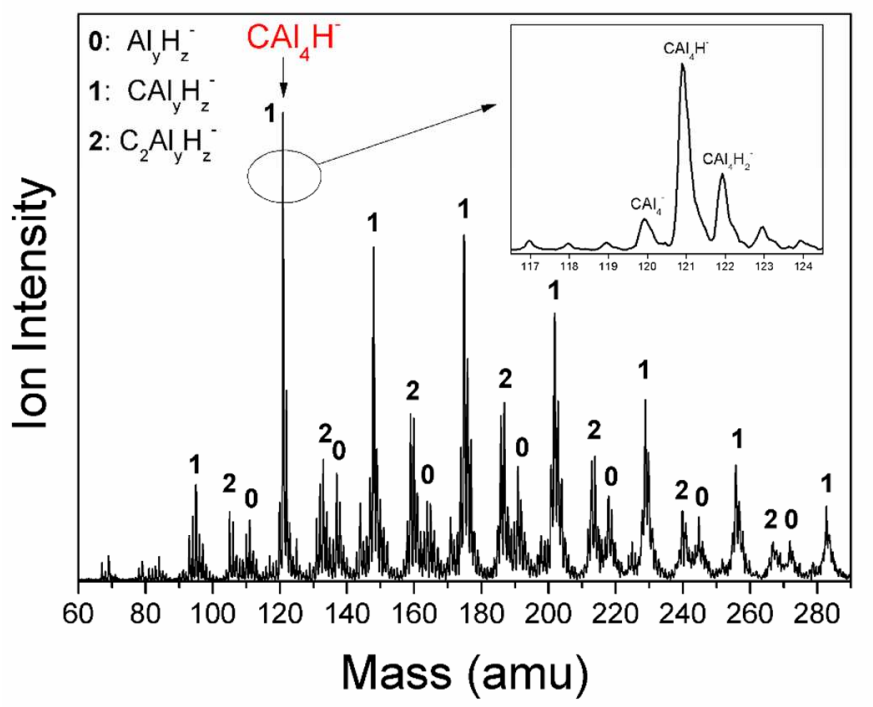

Figure 1. Mass spectrum of the $\mathrm{C}_{\mathrm{x}} \mathrm{Al}_{\mathrm{y}} \mathrm{H}_{\mathrm{z}}^{-}(\mathrm{x}=0-2, \mathrm{y}=1-9, \mathrm{z}=1-4)$ clusters.

When a cluster has reproducible intense mass spectral peak relative to its neighbors, it is a magic number species. To further investigate this magic cluster $\mathrm{CAl}_{4} \mathrm{H}^{-}$, we present its 
photoelectron spectrum in Figure 2, where an electron binding energy (EBE) band starts from 2.6 $\mathrm{eV}$ and peaks at $2.88 \mathrm{eV}$. The experimental electron affinity of neutral $\mathrm{CAl}_{4} \mathrm{H}$ can be determined to be $\sim 2.6 \mathrm{eV}$ from the threshold of the spectrum when there is enough Frank-Condon overlap between the anion and the neutral counterpart and when there is not too much hot band present. The experimental vertical detachment energies (VDE) of $\mathrm{CAl}_{4} \mathrm{H}^{-}$is determined to be the peak position, $2.88 \mathrm{eV}$, which is the middle one of the three vibrational progressions. This high detachment energy needed for $\mathrm{CAl}_{4} \mathrm{H}^{-}$again confirms its high stability, consistent with its high mass spectral intensity. The splitting of this EBE band, $0.09 \mathrm{eV}$, is close to the calculated 725.6 $\mathrm{cm}^{-1}$ vibrational mode of the neutral $\mathrm{CAl}_{4} \mathrm{H}$ cluster $\left(\mathbf{C A l}_{\mathbf{4}} \mathbf{H}-\mathbf{0 1}\right.$ at B3LYP/aug-cc-pVTZ level), which is associated with the in-plane swing of the central carbon and ligand hydrogen perpendicular to the Al-Al bond. This is reasonable because the photoelectron is detached from a molecular orbital that is delocalized within the whole cluster, which causes the bond displacement of the entire skeleton.

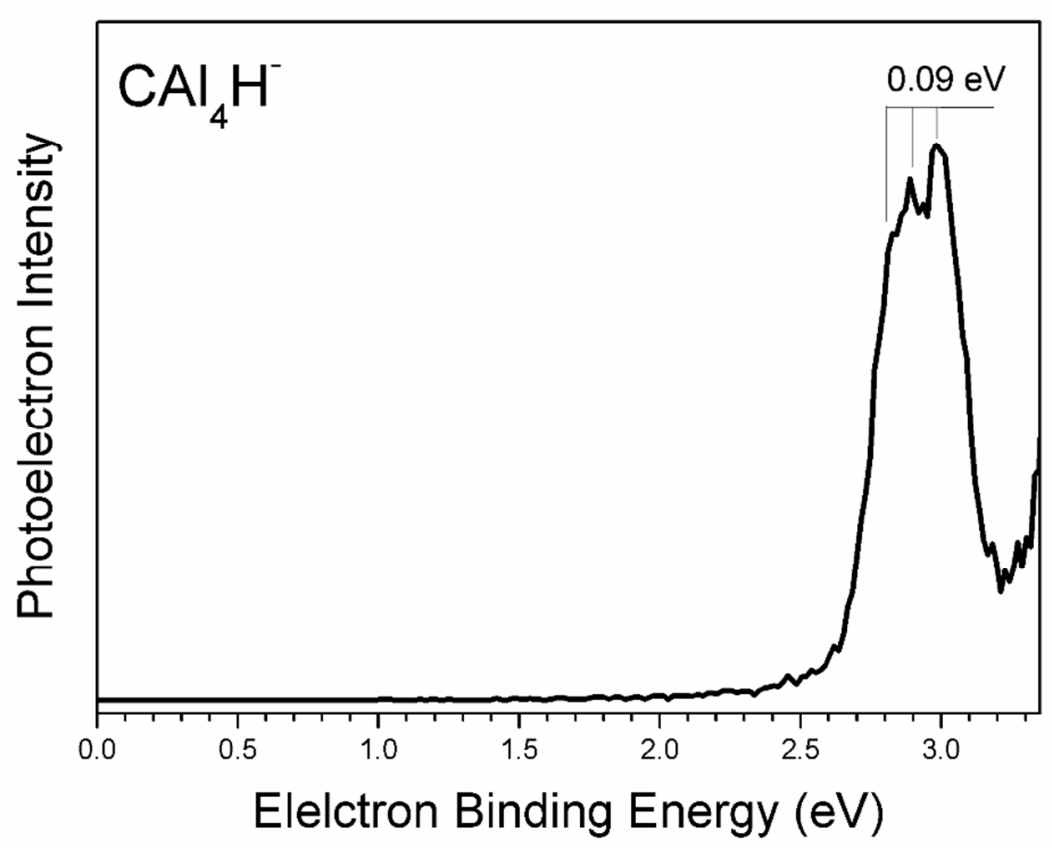

Figure 2. Photoelectron spectrum of the $\mathrm{CAl}_{4} \mathrm{H}^{-}$cluster. 
The global, unbiased, isomeric search utilizing the "grid" program (see SI for detail) obtained 32 local minima for $\mathrm{CAl}_{4} \mathrm{H}^{-}$and 41 local minima for $\mathrm{CAl}_{4} \mathrm{H}$ at the level of CBS-QB3. In order to improve the accuracy, high level B3LYP/aug-cc-pVTZ (for geometry and vibrational frequencies) and CCSD(T)/aug-cc-pVTZ (for single-point energy) calculations are performed for all the low-lying isomers ( $\triangle \mathrm{E}<10 \mathrm{kcal} / \mathrm{mol}$ at $\mathrm{CBS}-\mathrm{QB} 3$ level). Most of isomers of $\mathrm{CAl}_{4} \mathrm{H}^{-/ 0}$ have very high energies, for simplicity, we only show several low-lying isomers in Figure 3. Structures, Cartesian coordinates and total energies of high energy isomers can be found in the SI. As seen in Figure 3, $\mathbf{C A l}_{4} \mathbf{H}-\mathbf{0 1}$ and $\mathbf{C A l}_{4} \mathbf{H}_{-01}^{-0}$ featuring a ptC core are the ground state structures in each system. Unlike $\mathrm{CAl}_{4}$ and $\mathrm{CAl}_{4}{ }^{-}$that have the tetrahedral and planar skeletons, respectively, $\mathbf{C A l}_{4} \mathbf{H - 0 1}$ and $\mathbf{C A l}_{4} \mathbf{H}^{-} \mathbf{- 0 1}$ possess very similar skeleton with $\mathrm{C}_{2 \mathrm{v}}$ symmetry, the major difference is that one ligand-ligand bond (Al-Al bond) is broken in the neutral system by removing one electron. The two structures can be viewed as one H-bridge is added to the skeleton of $\mathrm{CAl}_{4}^{-}$, forming an $\mathrm{H}$-bridged ptC. Similar H-bridged structures have been found in many boranes and alanes. ${ }^{30}$ All the remaining isomers with higher energy in each system have terminal-H, among which $\mathbf{C A l}_{4} \mathbf{H - 0 3}, \mathbf{C A l}_{4} \mathbf{H}_{-04}$ and $\mathbf{C A l}_{4} \mathbf{H}_{-02}^{-}$also possess ptC structures.

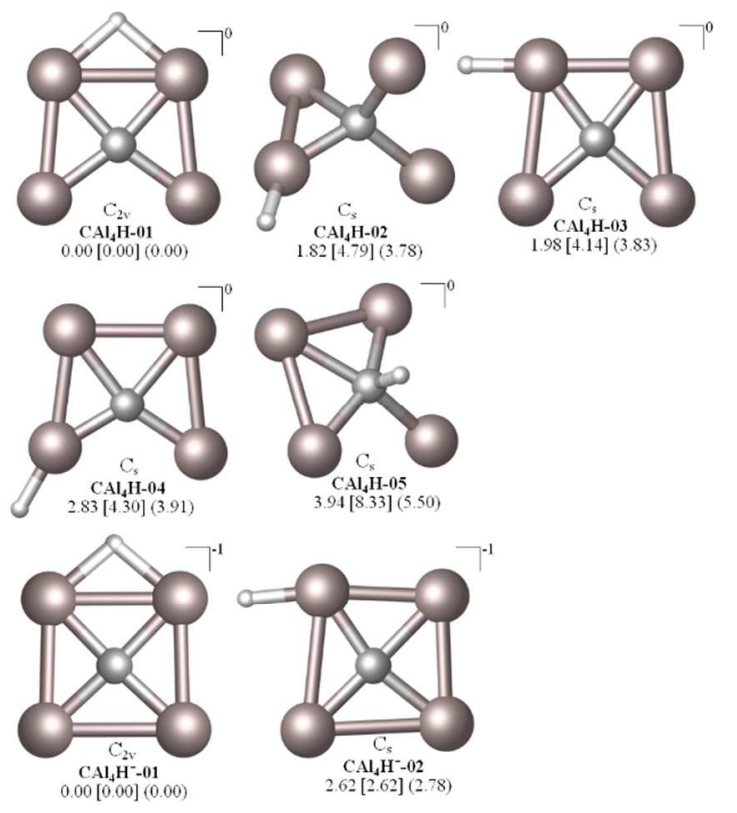


Figure 3. Structures and the relative energies (in $\mathrm{kcal} / \mathrm{mol}$ ) of the ground state and low-lying $\mathrm{ptC}$ structures at the CCSD(T)/aug-cc-pVTZ//B3LYP/aug-cc-pVTZ levels of theory. The values in square brackets are at the level of CBS-QB3, and the values in parenthesis are at B3LYP/aug-ccpVTZ level. All the energies are corrected by zero-point energy. The energies at CCSD(T)/augcc-pVTZ level were corrected using the zero-point energies obtained at B3LYP/aug-cc-pVTZ.
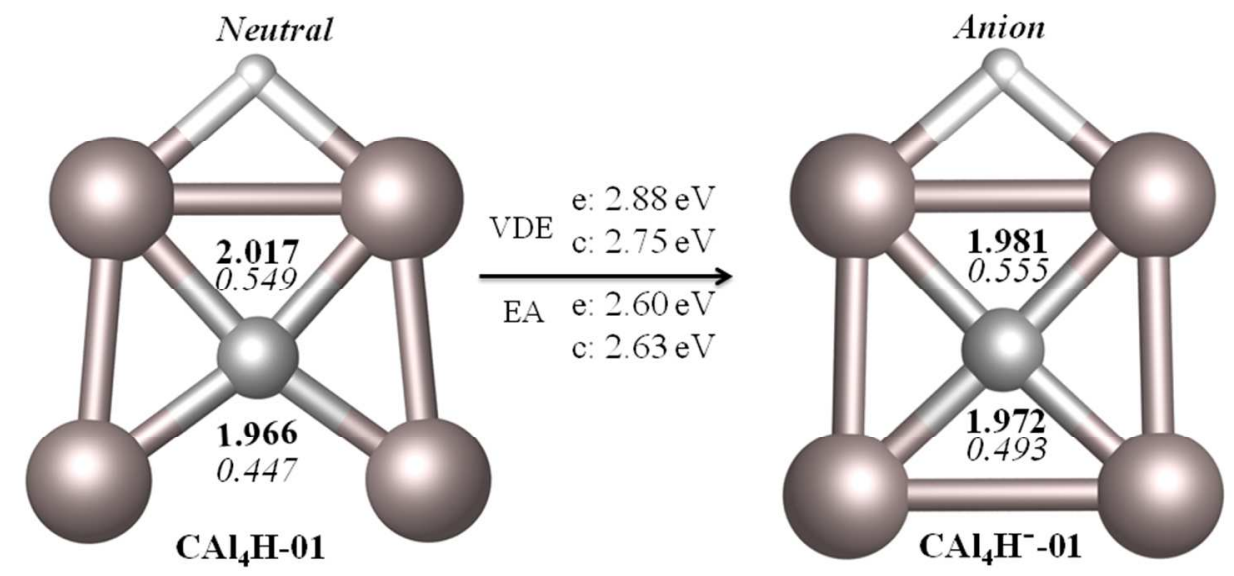

Figure 4. The key structural parameters, Wiberg Bond Indices (WBI) of C-Al bonds, experimental and calculated vertical detachment energies, adiabatic electron affinity of neutral $\mathrm{CAl}_{4} \mathrm{H}$ and anion $\mathrm{CAl}_{4} \mathrm{H}^{-}$ground state structures. e is short for experiment and $\mathrm{c}$ is short for calculation.

The four $\mathrm{C}-\mathrm{Al}$ bond lengths and the corresponding Wiberg Bond Indices (WBI) ${ }^{31}$ of two ground state structures are shown in Figure 4. The C-Al bond lengths range from $1.966 \AA$ to 2.017 $\AA$, and each $\mathrm{WBI}_{\mathrm{C}-\mathrm{Al}}$ is around 0.5 . These values indicate the bonds between the central Catom and the ligand $\mathrm{Al}$-atoms are single bonds. The $\mathrm{ptC}$ feature also can be demonstrated from the molecular orbitals. In Figure 5, the molecular orbitals (MO) HOMO-3 (for $\mathrm{CAl}_{4} \mathrm{H}$ ) and HOMO-4 (for $\mathrm{CAl}_{4} \mathrm{H}^{-}$) are delocalized $\pi$-orbitals, which are crucial to achieving the planar geometry and are aromatic. Meanwhile, $\mathrm{HOMO}-4$ (for $\left.\mathrm{CAl}_{4} \mathrm{H}\right)$ and $\mathrm{HOMO}-3$ (for $\mathrm{CAl}_{4} \mathrm{H}^{-}$) are 
delocalized ligand-ligand $\sigma$ bonding. Addition of one electron reverses the order of delocalized $\pi$ and $\sigma$ orbitals. One can observe that the hydrogen is actively hybridized in several MOs (ligandligand and center-ligand), making the electron of hydrogen part of the skeleton. Interestingly, with reference to the $18 \mathrm{e}-\mathrm{CAl}_{4}{ }^{2-}$, the hydrogen in $\mathrm{CAl}_{4} \mathrm{H}^{-}$strengthens the neighboring $\mathrm{Al}-\mathrm{Al}$ bonds, whereas Na weakens them in $\mathrm{NaCAl}_{4}{ }^{-}$(Figure S1).

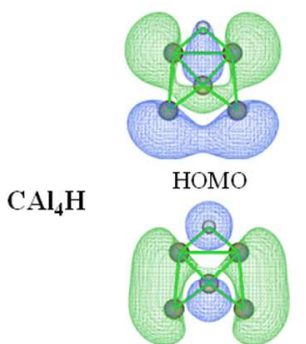

HOMO-4
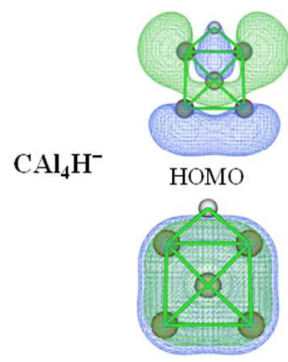

HOMO-4

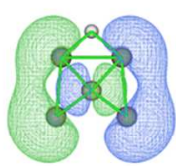

HOMO-1

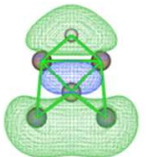

HOMO-5

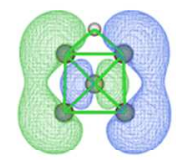

HOMO-1

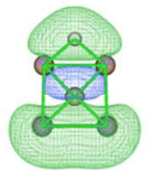

HOMO-5
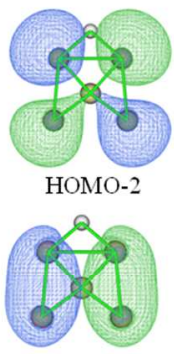

HOMO-6

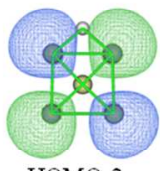

HOMO-2

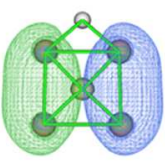

HOMO-6

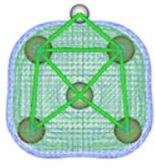

HOMO-3

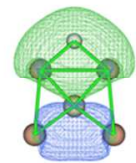

HOMO-7

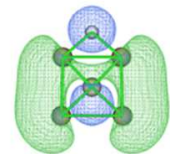

HOMO-3

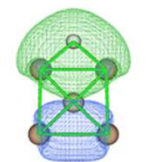

HOMO-7

Figure 5. Molecular orbitals of neutral $\mathrm{CAl}_{4} \mathrm{H}$ and anion $\mathrm{CAl}_{4} \mathrm{H}^{-}$ground state structures at the level of B3LYP/aug-cc-pVTZ.

In order to compare with the experiment, the vertical detachment energies (VDE) and the adiabatic electron affinity (EA) were calculated at the level of $\operatorname{CCSD}(\mathrm{T}) /$ aug-ccpVTZ//B3LYP/aug-cc-pVTZ (see Figure 4). The VDE represents the difference in energy between $\mathrm{CA}_{14} \mathrm{H}^{-}$in its ground state and neutral $\mathrm{CA} 14 \mathrm{H}$ having the anion geometry. EA is the energy difference between the ground states of the neutral and the anionic clusters. Due to the same structure between the neutral ground state and the neutral equilibrium structure with 
anionic geometry, the EA and adiabatic detachment energy ADE have the same values. For the two low-lying isomers of $\mathrm{CAl}_{4} \mathrm{H}^{-}$, the calculated $\mathrm{VDE}$ is $2.75 \mathrm{eV}$ for $\mathrm{CAl}_{4} \mathrm{H}^{-}-01$ and $2.78 \mathrm{eV}$ for $\mathrm{CAl}_{4} \mathrm{H}^{-}-02$; both agree well with the experimental $2.88 \mathrm{eV}$. The calculated EA and ADE are 2.63 $\mathrm{eV}$ for $\mathrm{CAl}_{4} \mathrm{H}^{-}-01$ and $2.60 \mathrm{eV}$ for $\mathrm{CAl}_{4} \mathrm{H}^{-}-02$, which are also very close to the experimental value $2.60 \mathrm{eV}$. However, $\mathbf{C A l}_{\mathbf{4}} \mathbf{H}^{-} \mathbf{- 0 2}$, a terminal-H ptC, has a slightly higher energy (around 2 $\mathrm{kcal} / \mathrm{mol}$ at three different levels) than $\mathbf{C A l}_{\mathbf{4}} \mathbf{H}^{-}-\mathbf{0 1}$ with a $\mathrm{H}$-bridged $\mathrm{ptC}$. We further studied the interconversion between the terminal-H and $\mathrm{H}$-bridged ptC structures. In Figure $\mathrm{S} 2$, at the B3LYP/6-311G(2d,d,p) level without zero-point energy correction, the barrier is negligibly small as $0.01 \mathrm{kcal} / \mathrm{mol}$ for neutral system and $0.03 \mathrm{kcal} / \mathrm{mol}$ for anion system. At the sophisticated CBS-QB3 level including zero-point energy correction, the barrier values become slightly negative, which is a reasonable result of computing the higher-level energy at a lower-level geometry. If the Gibbs free energy is concerned, the conversion barriers from the terminal-H ptC to $\mathrm{H}$-bridged $\mathrm{ptC}$ structures are 0.67 and $1.33 \mathrm{kcal} / \mathrm{mol}$ at $298.15 \mathrm{~K}$ and $450 \mathrm{~K}$ (experimental temperature), respectively. Therefore, the terminal-H structure is very easy to transfer to the $\mathrm{H}$ bridged structure, and coexistence of $\mathbf{C A l}_{4} \mathbf{H}_{-\mathbf{- 0 2}}^{-}$is unlikely in the experiment. The good agreement between theory and experiment indicates that the ground $\mathrm{ptC} \mathrm{H}$-bridged $\mathrm{ptC}$ states of $\mathrm{CAl}_{4} \mathrm{H}^{-/ 0}$ were detected.

Based on the above discussion, the most stable $\mathbf{C A l}_{\mathbf{4}} \mathbf{H - 0 1}$ and $\mathbf{C A l}_{\mathbf{4}} \mathbf{H - 0 1}$ are demonstrated as ptC with a bridging-H. The hydrogen atom effectively donates its electron to the skeleton by hybridization in several molecular orbitals, which is supported by the MOs in Figure 5. Thus, for anionic $\mathbf{C A l}_{4} \mathbf{H - 0 1}^{-}$with a bridging-H motif, the skeleton has $4+3 \times 4=16$ electrons available from the carbon and aluminum atoms, plus 1 electron from the bridged hydrogen atom and 1 electron from negative charge, summing to a total of 18 electrons. Similarly, the neutral $\mathbf{C A l}_{4} \mathbf{H}-\mathbf{0 1}$ has 17 
electrons. In the terminal-H motif on the other hand, the Al-H bond consumes two electrons to form a localized $\sigma$ bond (the occupation number is 1.96 according to NBO calculations), which cannot contribute to the delocalization of the skeleton. Thus, these higher energy anionic isomers with a terminal-H only have 16 electrons available. Accordingly, the higher energy neutral isomers with a terminal-H have 15 electrons, and the molecular orbitals are shown in Figure S3. This directly demonstrates that the bridging- $\mathrm{H}$ isomers with $17 / 18 \mathrm{e}$ are more stable than the terminal-H isomers with $15 / 16$ e. While previously studied $17 / 18$ e species mainly comprise the metalized or organometallized ptC cores, the presently identified hydrogenated ptCs have expanded our knowledge on ptC.

In summary, the hydrogenated planar tetracoordinate carbon species $\mathrm{CAl}_{4} \mathrm{H}$ and $\mathrm{CAl}_{4} \mathrm{H}^{-}$have been identified theoretically and experimentally for the first time. They both contain the ptC core with a bridging- $\mathrm{H}$ as the global minima. The hydrogen atom, even though known to be able to bind to diverse sites, selectively bind to the bridging site in lieu of the terminal sites, demonstrating that the $17 \mathrm{e} / 18 \mathrm{e}$ ptCs with bridging-H are more stable than $15 \mathrm{e} / 16 \mathrm{e}$ ptCs with terminal-H, making it a good example of the success of the electron counting rules. Experiment and theory have demonstrated and interpreted the unusual stability of $\mathrm{CAl}_{4} \mathrm{H}^{-}$, which can be understood by its electronic structures and molecular orbitals.

\section{ASSOCIATED CONTENT}

Supporting Information. Detailed description of the experimental and theoretical methods; structures, total energies and the Cartesian coordinates of all the isomers; the barrier between the bridging- $\mathrm{H}$ ptC and the terminal-H ptC; molecular orbitals of the terminal- $\mathrm{H}$ ptC.

\section{AUTHOR INFORMATION}




\section{Corresponding Author}

*E-mail: zhangx@caltech.edu ;*E-mail: yhdd@jlu.edu.cn ;*E-mail: kbowen@jhu.edu

${ }^{+}$These authors contributed equally to this work.

${ }^{\S}$ Present Address: Department of Chemistry, University of California, Irvine, CA 92697, USA

Notes

The authors declare no competing financial interests.

\section{ACKNOWLEDGMENT}

The theoretical work was supported by the National Natural Science Foundation of China (No. 21273093, 21473069, 21073074) (YHD). This material is based upon work supported by the Air Force Office of Scientific Research (AFOSR), under Grant No. FA9550-15-1-0259 (KHB).

\section{REFERENCES}

(1) Keese, R. Carbon Flatland: Planar Tetracoordinate Carbon and Fenestranes. Chem. Rev. 2006, 106, 4787-4808.

(2) Yang, L.-M.; Ganz, E.; Chen, Z.; Wang, Z.-X.; Schleyer, P. von R. Four Decades of the Chemistry of Planar Hypercoordinate Compounds. Angew. Chem. Int. Ed. 2015, 54, 94689501.

(3) Monkhorst, H. J. Activation Energy for Interconversion of Enantiomers Containing an Asymmetric Carbon Atom without Breaking Bonds. Chem. Commun. Lond. 1968, No. 18, 1111-1112.

(4) Hoffmann, R.; Alder, R. W.; Wilcox, C. F. Planar Tetracoordinate Carbon. J. Am. Chem. Soc. 1970, 92, 4992-4993.

(5) Collins, J. B.; Dill, J. D.; Jemmis, E. D.; Apeloig, Y.; Schleyer, P. v. R.; Seeger, R.; Pople, J. A. Stabilization of Planar Tetracoordinate Carbon. J. Am. Chem. Soc. 1976, 98, 54195427.

(6) Pei, Y.; An, W.; Ito, K.; Schleyer, P. von R.; Zeng, X. C. Planar Pentacoordinate Carbon in $\mathrm{CAl}_{5}{ }^{+}$: A Global Minimum. J. Am. Chem. Soc. 2008, 130, 10394-10400.

(7) Wang, Z.-X.; Schleyer, P. von R. Construction Principles of "Hyparenes": Families of Molecules with Planar Pentacoordinate Carbons. Science 2001, 292, 2465-2469. 
(8) Exner, K.; Schleyer, P. von R. Planar Hexacoordinate Carbon: A Viable Possibility. Science 2008, 290, 1937-1940.

(9) Boldyrev, A. I.; Li, X.; Wang, L.-S. Experimental Observation of Pentaatomic Tetracoordinate Planar Si- and Ge-Containing Molecules: $\mathrm{MAl}_{4}{ }^{-}$and $\mathrm{MAl}_{4}$. Angew. Chem. Int. Ed. 2000, 39, 3307-3310.

(10) Islas, R.; Heine, T.; Ito, K.; Schleyer, P. v. R.; Merino, G. Boron Rings Enclosing Planar Hypercoordinate Group 14 Elements. J. Am. Chem. Soc. 2007, 129, 14767-14774.

(11) Menzel, M.; Steiner, D.; Winkler, H.-J.; Schweikart, D.; Mehle, S.; Fau, S.; Frenking, G.; Massa, W.; Berndt, A. Compounds with Planar Tetracoordinate Boron Atoms: Anti van't Hoff/Le Bel Geometries without Metal Centers. Angew. Chem. Int. Ed. Engl. 1995, 34, 327-329.

(12) Li, Y.; Liao, Y.; Chen, Z. Be ${ }_{2} \mathrm{C}$ Monolayer with Quasi-Planar Hexacoordinate Carbons: A Global Minimum Structure. Angew. Chem. Int. Ed. 2014, 53, 7248-7252.

(13) Li, Y.; Liao, Y.; Schleyer, P. von R.; Chen, Z. $\mathrm{Al}_{2} \mathrm{C}$ Monolayer: The Planar Tetracoordinate Carbon Global Minimum. Nanoscale 2014, 6, 10784-10791.

(14) Zhang, Z.; Liu, X.; Yakobson, B. I.; Guo, W. Two-Dimensional Tetragonal TiC Monolayer Sheet and Nanoribbons. J. Am. Chem. Soc. 2012, 134, 19326-19329.

(15) Röttger, D.; Erker, G. Compounds Containing Planar-Tetracoordinate Carbon. Angew. Chem. Int. Ed. Engl. 1997, 36, 812-827.

(16) Cotton, F. A.; Millar, M. The Probable Existence of A Triple Bond Between Two Vanadium Atoms. J. Am. Chem. Soc. 1977, 99, 7886-7891.

(17) Li, X.; Wang, L.-S.; Boldyrev, A. I.; Simons, J. Tetracoordinated Planar Carbon in the $\mathrm{Al}_{4} \mathrm{C}^{-}$Anion. A Combined Photoelectron Spectroscopy and Ab Initio Study. J. Am. Chem. Soc. 1999, 121, 6033-6038.

(18) Wang, L.-S.; Boldyrev, A. I.; Li, X.; Simons, J. Experimental Observation of Pentaatomic Tetracoordinate Planar Carbon-Containing Molecules. J. Am. Chem. Soc. 2000, 122, 76817687.

(19) Boldyrev, A. I.; Wang, L.-S. Beyond Classical Stoichiometry: Experiment and Theory. $J$. Phys. Chem. A 2001, 105, 10759-10775.

(20) Li, X.; Zhang, H.-F.; Wang, L.-S.; Geske, G. D.; Boldyrev, A. I. Pentaatomic Tetracoordinate Planar Carbon, $\left[\mathrm{CAl}_{4}\right]^{2-}$ : A New Structural Unit and Its Salt Complexes. Angew. Chem. Int. Ed. 2000, 39, 3630-3632.

(21) Schleyer, P. von R.; Boldyrev, A. I. A New, General Strategy for Achieving Planar Tetracoordinate Geometries for Carbon and Other Second Row Periodic Elements. J. Chem. Soc. Chem. Commun. 1991, No. 21, 1536-1538.

(22) Boldyrev, A. I.; Simons, J. Tetracoordinated Planar Carbon in Pentaatomic Molecules. $J$. Am. Chem. Soc. 1998, 120, 7967-7972.

(23) Langmuir, I. Types of Valence. Science 1921, 54, 59-67.

(24) Mitchell, P. R.; Parish, R. V. The Eighteen Electron Rule. J. Chem. Educ. 1969, 46, 811814.

(25) Jensen, W. B. The Origin of the 18-Electron Rule. J. Chem. Educ. 2005, 82, 28.

(26) Averkiev, B. B.; Zubarev, D. Y.; Wang, L.-M.; Huang, W.; Wang, L.-S.; Boldyrev, A. I. Carbon Avoids Hypercoordination in $\mathrm{CB}_{6}{ }^{-}, \mathrm{CB}_{6}{ }^{2-}$, and $\mathrm{C}_{2} \mathrm{~B}_{5}{ }^{-}$Planar Carbon-Boron Clusters. J. Am. Chem. Soc. 2008, 130, 9248-9250. 
(27) Crigger, C.; Wittmaack, B. K.; Tawfik, M.; Merino, G.; Donald, K. J. Plane and Simple: Planar Tetracoordinate Carbon Centers in Small Molecules. Phys. Chem. Chem. Phys. 2012, 14, 14775.

(28) Li, S.-D.; Ren, G.-M.; Miao, C.-Q.; Jin, Z.-H. $\mathrm{M}_{4} \mathrm{H}_{4} \mathrm{X}$ : Hydrometals $(\mathrm{M}=\mathrm{Cu}, \mathrm{Ni})$ Containing Tetracoordinate Planar Nonmetals $(\mathrm{X}=\mathrm{B}, \mathrm{C}, \mathrm{N}, \mathrm{O})$. Angew. Chem. Int. Ed. 2004, 43, 1371-1373.

(29) Wu, Y.-B.; Li, Z.-X.; Pu, X.-H.; Wang, Z.-X. Design of Molecular Chains Based on the Planar Tetracoordinate Carbon Unit $\mathrm{C}_{2} \mathrm{Al}_{4}$. J. Phys. Chem. C 2011, 115, 13187-13192.

(30) Aldridge, S.; Downs, A. J. Hydrides of the Main-Group Metals: New Variations on an Old Theme. Chem. Rev. 2001, 101, 3305-3366.

(31) Wiberg, K. B. Application of The Pople-Santry-Segal CNDO Method to the Cyclopropylcarbinyl and Cyclobutyl Cation and to Bicyclobutane. Tetrahedron 1968, 24, 1083-1096. 


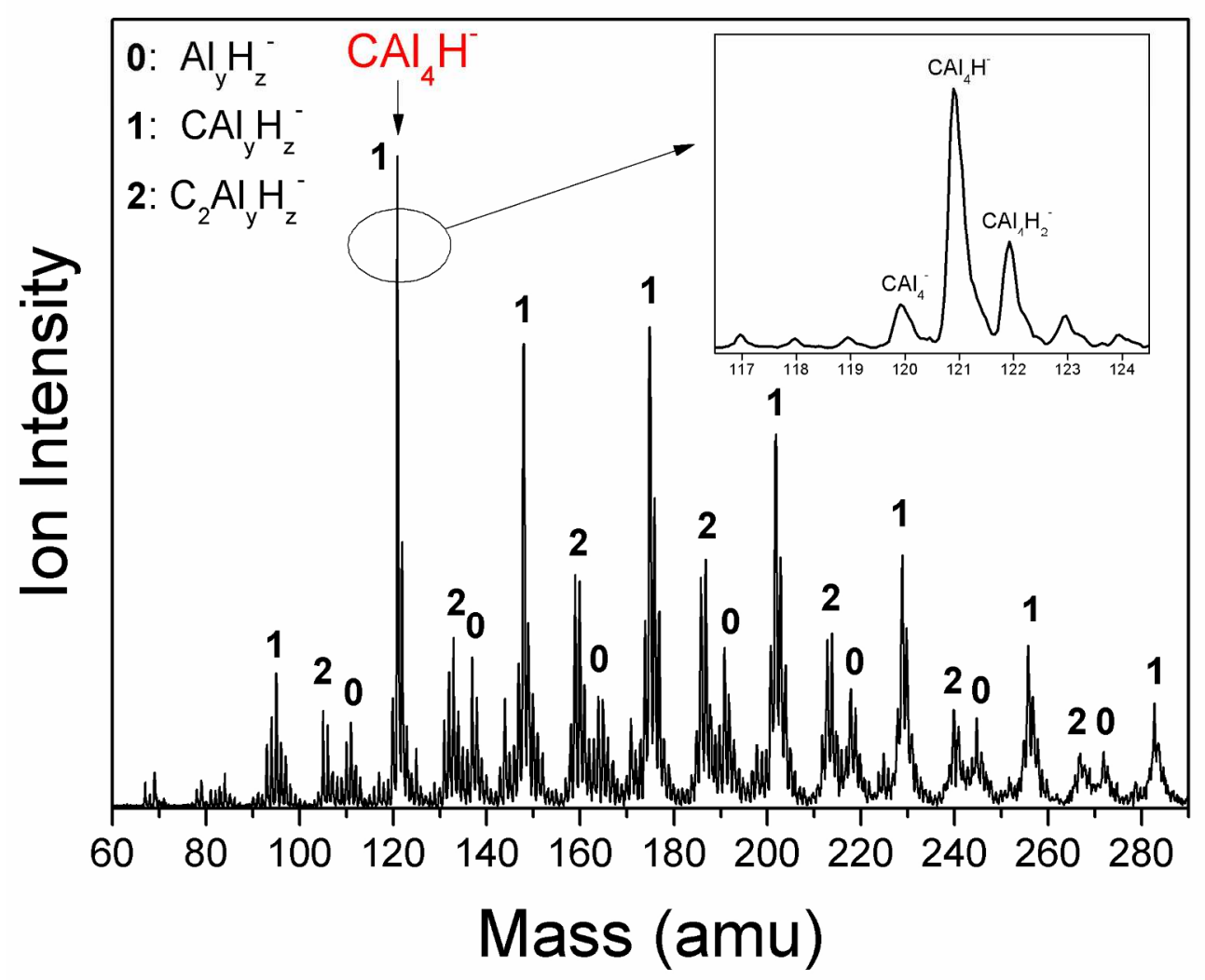

Figure 1

$390 \times 328 \mathrm{~mm}(150 \times 150 \mathrm{DPI})$ 


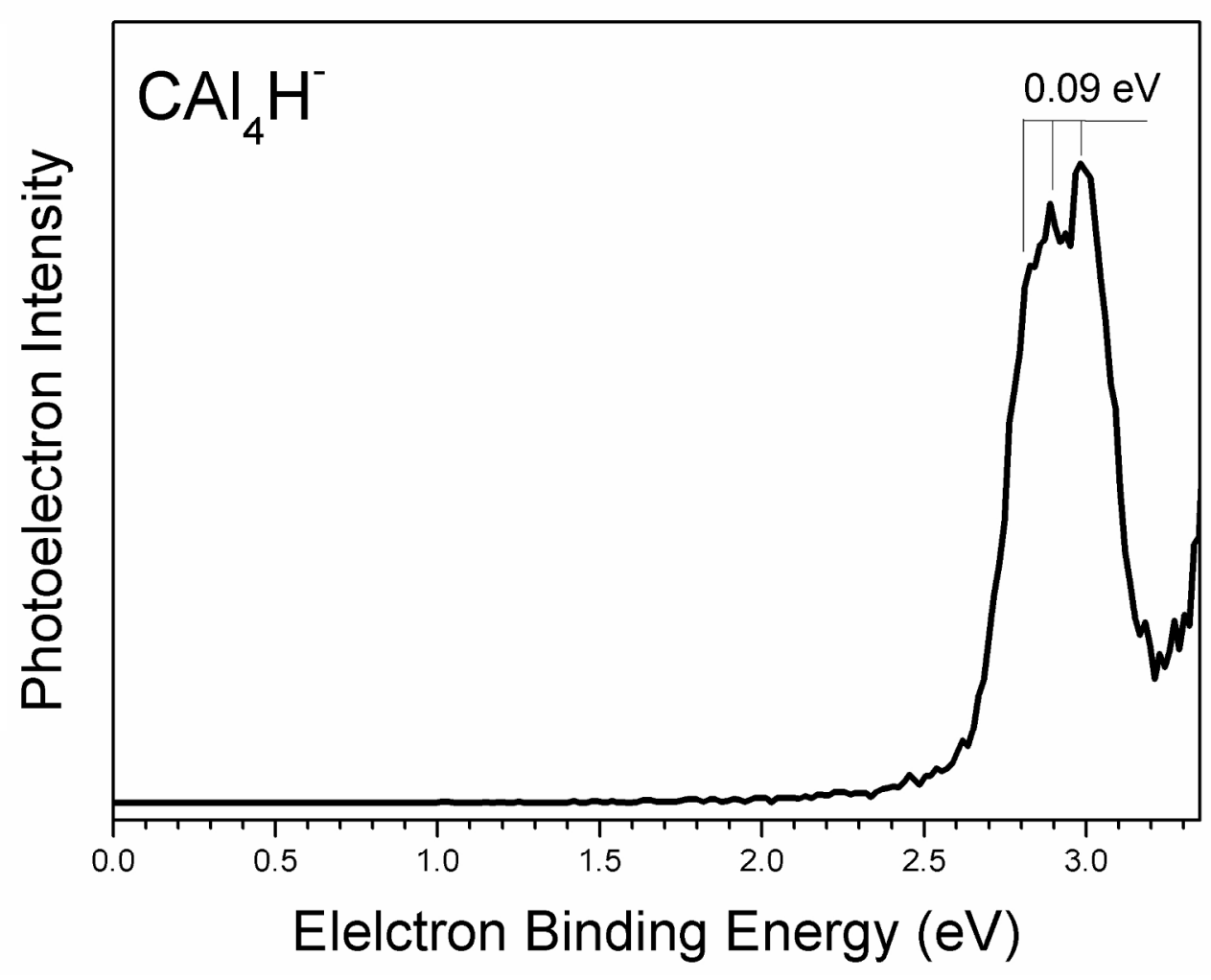

Figure 2

$398 \times 310 \mathrm{~mm}(150 \times 150 \mathrm{DPI})$ 

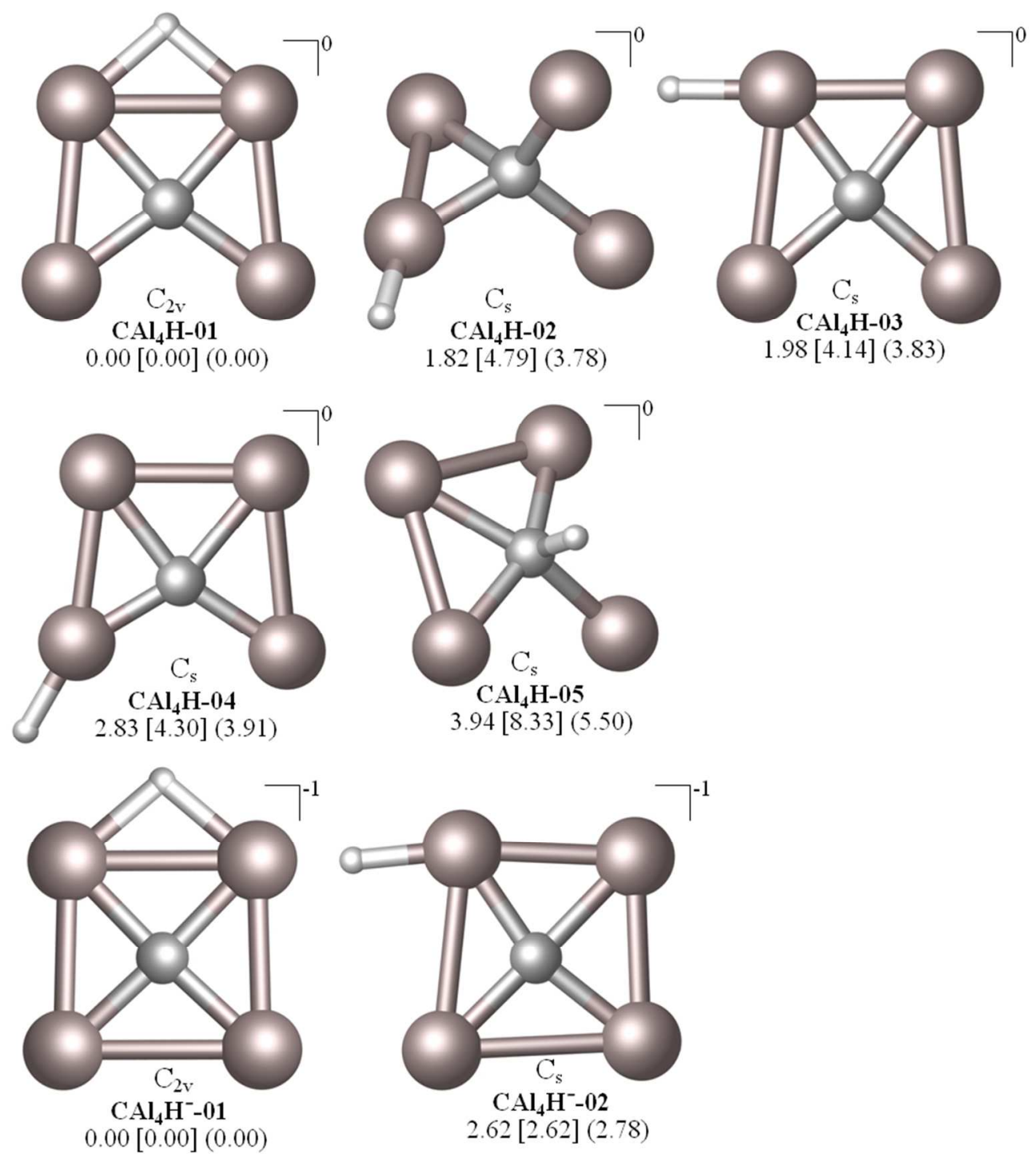

Figure 3

$254 \times 280 \mathrm{~mm}(96 \times 96$ DPI) 

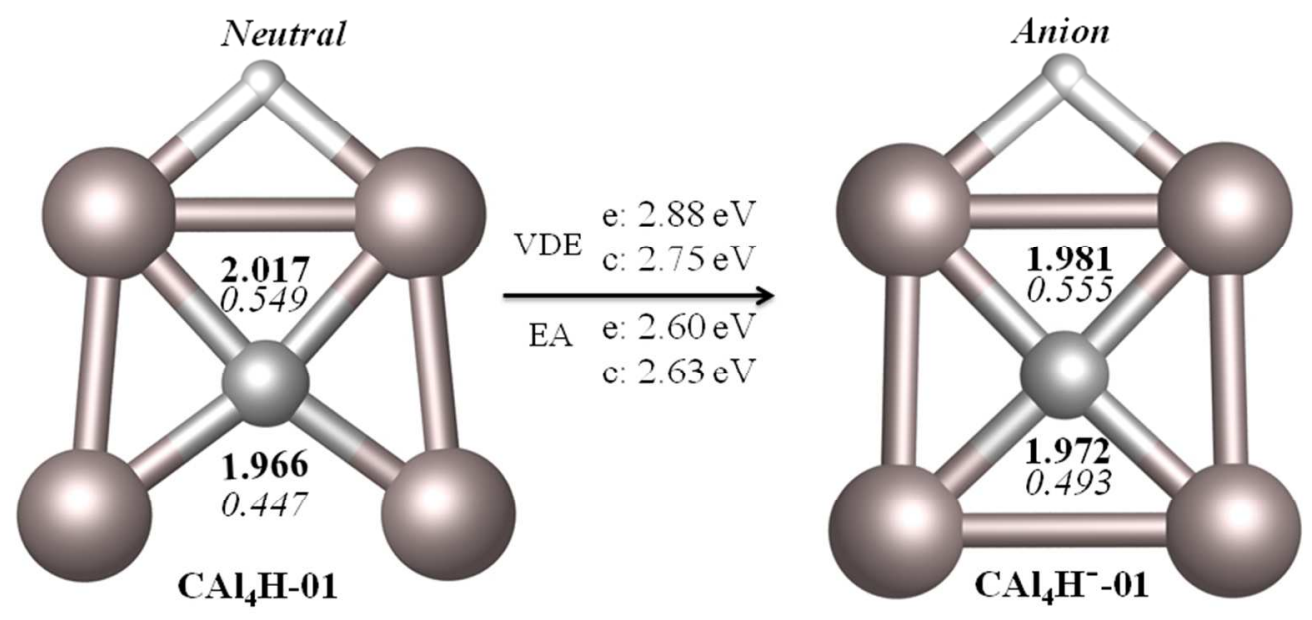

Figure 4

$243 \times 118 \mathrm{~mm}(96 \times 96$ DPI) 


1
2
3
4
5
6
7
8
9
10
11
12
13
14
15
16
17
18
19
20
21
22
23
24
25
26
27
28
29
30
31
32
33
34
35
36
37
38
39
40
59
50
50
49
50
51
52
53
44
54

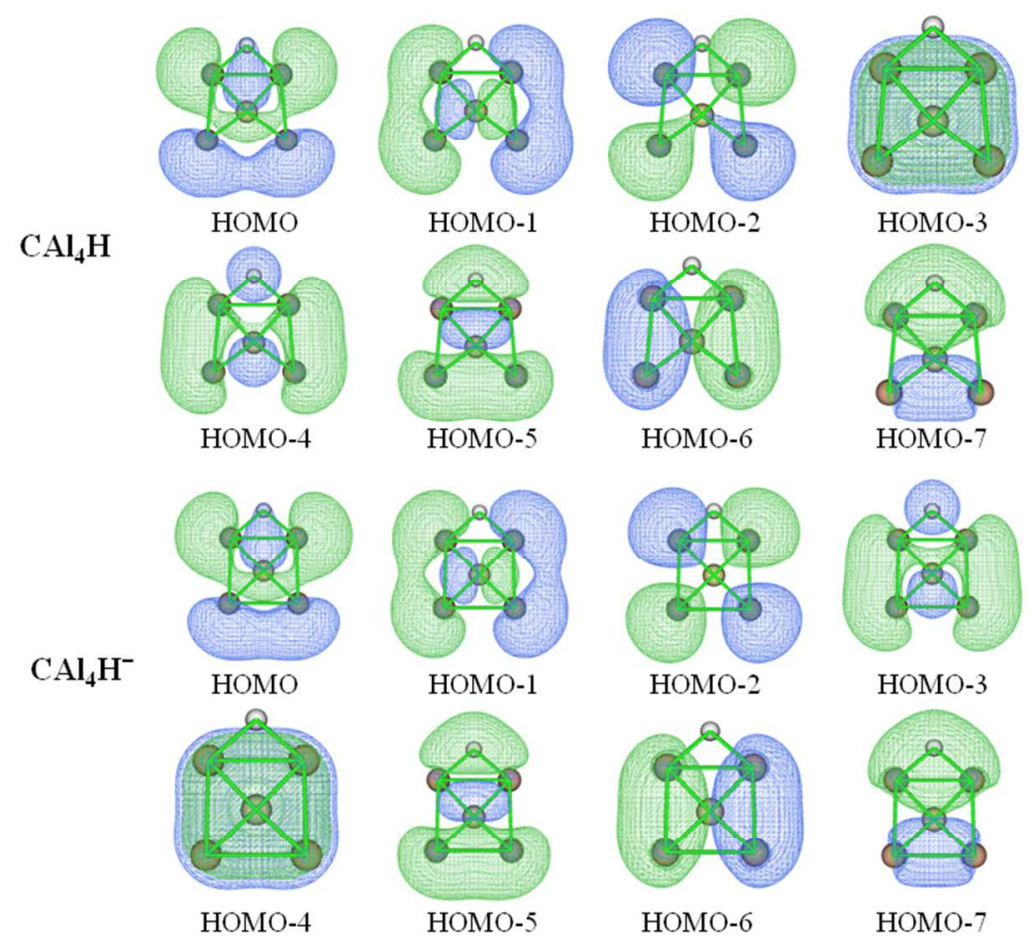

Figure 5 $254 \times 190 \mathrm{~mm}(96 \times 96 \mathrm{DPI})$ 


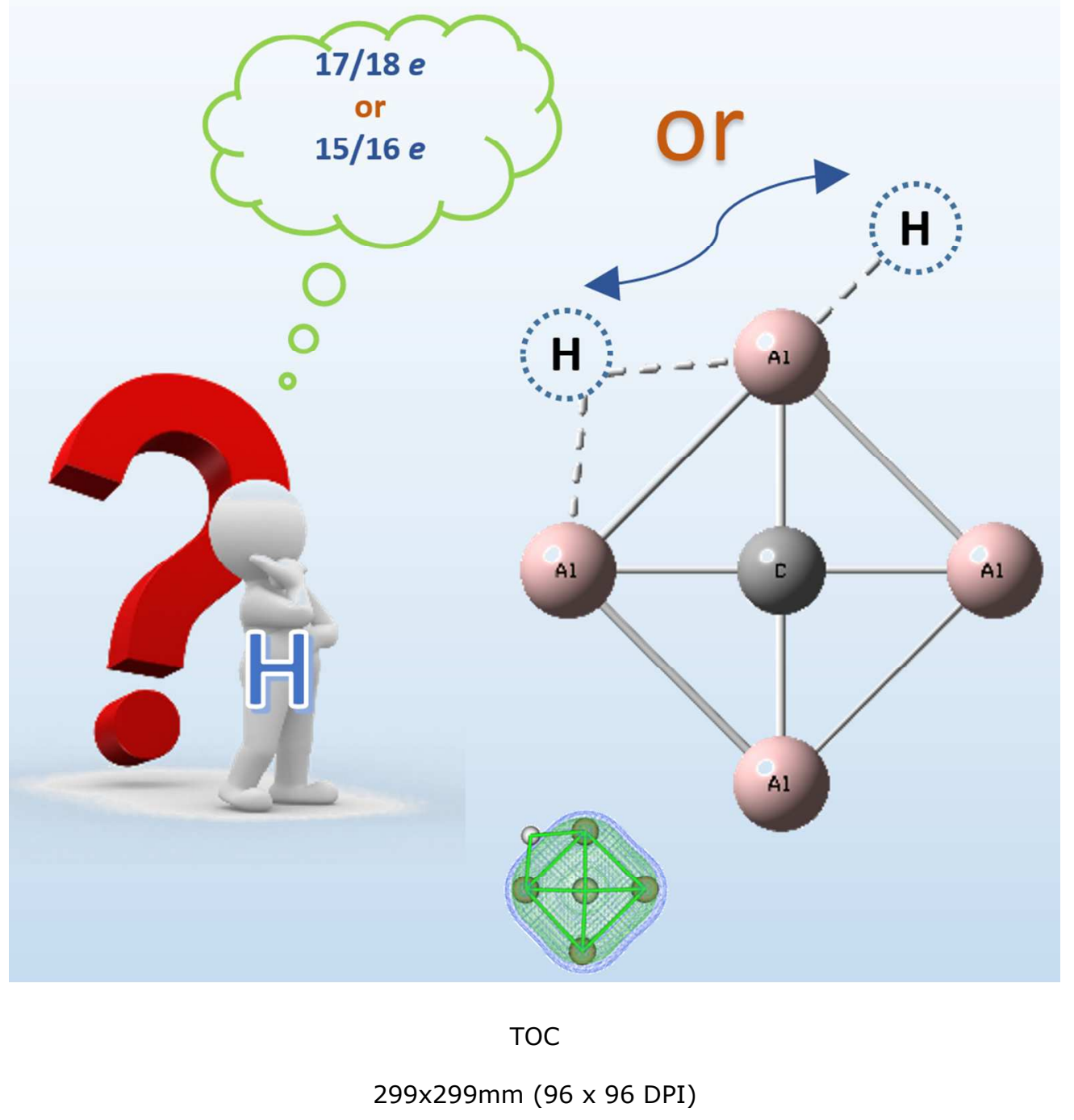

